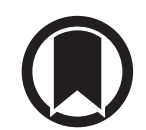

CrossMark

\section{Why asthma might surprisingly protect against poor outcomes in COVID-19}

\author{
To the Editor:
}

We read with interest the study by BEURNIER et al. [1] describing a lower prevalence of asthma (4.8\%) in a cohort of 768 patients hospitalised with coronavirus disease 2019 (COVID-19) compared to the general population, none of whom presented with an asthma exacerbation and only one who was treated for bronchospasm. This subgroup also had significantly reduced mortality compared to a control group without asthma. These findings must be considered preliminary given that they arise from a relatively small, single-centre cohort. In particular, the control group differed significantly in age (older) and gender balance (greater male/female ratio); both characteristics are associated worse outcomes and this raises the possibility that the results represent a statistical artefact. However, if corroborated, these data reflect a surprising departure from previous respiratory viral pandemics, most recently the 2009 H1N1/influenza A outbreak, where asthma was observed to be a major comorbidity in patients requiring hospitalisation ( $25 \%$ of admissions in a UK series [2]). Asthma was subsequently shown to be associated with an increased risk of acquisition of H1N1/influenza A virus [3] and consequent exacerbation [4]. Strikingly, the original severe acute respiratory syndrome coronavirus (SARS-CoV-1) pandemic was also characterised by an extremely low prevalence of chronic lung disease comorbidities [5], further suggesting that SARS-associated coronaviruses may not exacerbate asthma to the same extent as other respiratory viruses.

The mechanisms underlying this phenomenon are unknown. The authors propose two hypotheses to explain their observations: a lower expression of angiotensin-converting enzyme 2 (ACE2), the putative viral entry receptor for SARS-CoV-2, in asthma and/or a protective effect of inhaled corticosteroids (ICS), a mainstay of maintenance treatment in asthma that is linked to reduced sputum ACE2 expression $[6,7]$. We suggest three further hypothetical mechanisms. First, behavioural factors are likely to be important. Protective shielding for at-risk groups, including those with asthma, has been widely advocated by international guidelines. Reduced exposure to SARS-CoV-2 amongst patients with asthma may therefore be contributing to the low prevalence of asthma reported in hospitalised cohorts. However, the low rates of chronic respiratory illnesses in case series from the start of the pandemic before social distancing measures were introduced, suggests this cannot be the sole explanation. Government policies to limit the spread of the pandemic have also led to reductions in air pollution, which increases the severity of virus-induced asthma exacerbations [8].

Secondly, chronic inflammation in asthmatic lungs, arising from repeated epithelial insults by aeroallergens, pollutants and viruses, may lead to a degree of immune tolerance that could in turn act to restrict the development of the excessive inflammatory response that drives severity in COVID-19. Accordingly, pre-existing asthma was associated with reduced systemic inflammation in patients hospitalised with influenza [9], and reduced sepsis and sepsis-related mortality in pneumonia [10]. Type 2 inflammation, present in $\sim 50 \%$ of those with asthma, also protects against the development of sepsis in experimental models of bacterial respiratory infection [11].

Finally, mucus hypersecretion, a hallmark of asthma, may prevent SARS-CoV-2 from reaching the distal lung and protect from pathology. Secreted mucus, rich in mucin glycoproteins such as Muc5ac, acts as a first line of defence against infection. Asthma is associated with increased expression of MUC5AC [12] which, when over-expressed in transgenic mice, protects against influenza infection with reduced viral loads and attenuated cellular airway inflammation compared to wild-type controls [13]. It is thus conceivable that mucus hypersecretion in individuals with asthma prevents SARS-CoV-2 from penetrating

@ERSpublications

Asthma may protect against poor outcomes in COVID-19 due to several possible mechanisms, including altered viral entry receptor expression, inhaled corticosteroid use, chronic inflammation, reduced exposure due to shielding and/or mucus hypersecretion https://bit.ly/3eiXOPP

Cite this article as: Farne $\mathrm{H}$, Singanayagam A. Why asthma might surprisingly protect against poor outcomes in COVID-19. Eur Respir J 2020; 56: 2003045 [https://doi.org/10.1183/13993003.03045-2020]. 


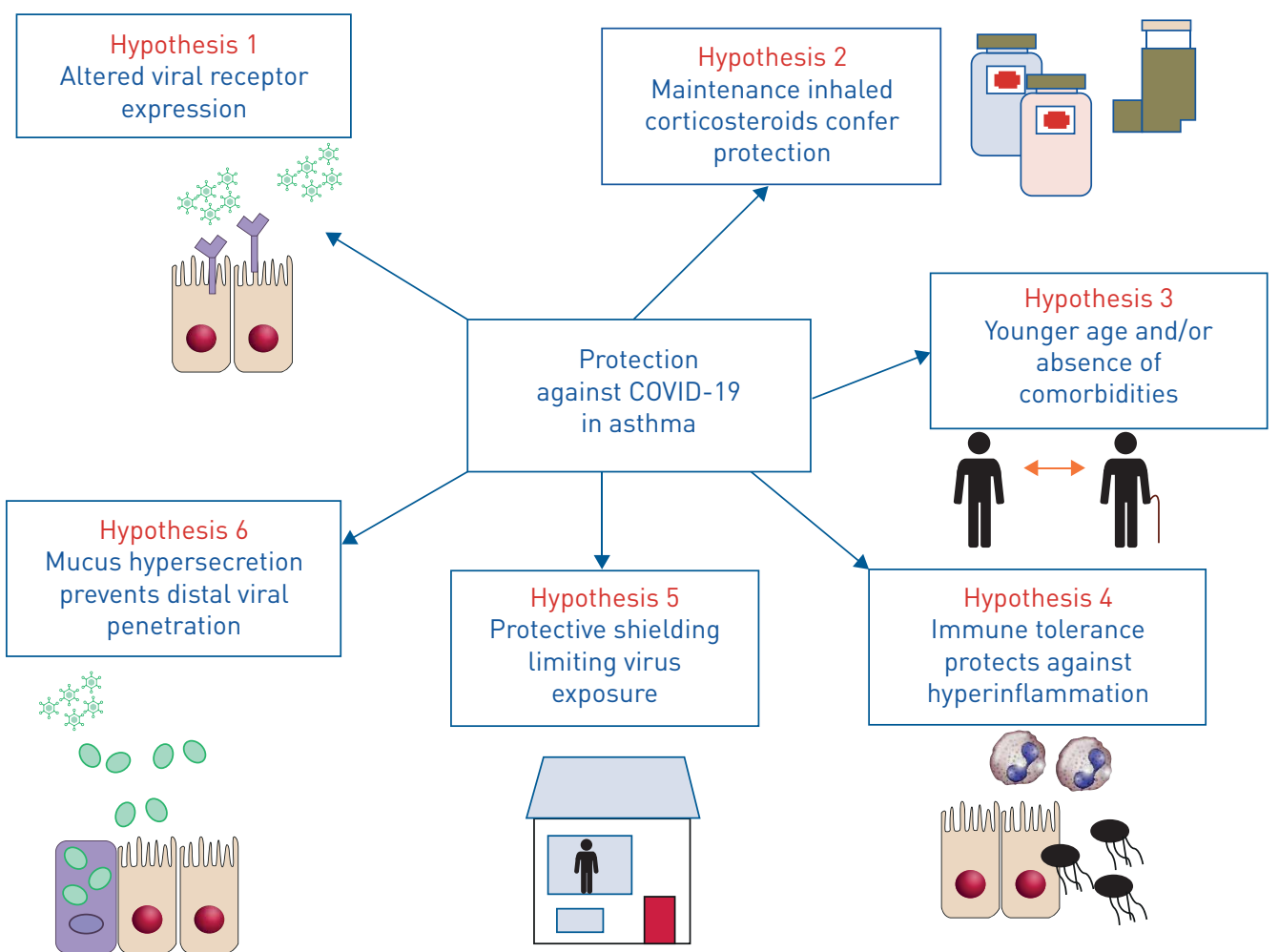

FIGURE 1 Hypotheses to explain the low prevalence of asthma in patients hospitalised with coronavirus disease 2019 (COVID-19) and relatively improved outcomes in these patients.

far enough to gain access to the alveolar type 2 cells, the cells predominantly expressing ACE2 in the lung. However, mucus hypersecretion is not present in all patients with asthma and may therefore only confer protection in some individuals. It is also notable that other conditions characterised by high sputum burden and increased mucins (e.g. COPD) are, in contrast, associated with poor outcomes from COVID-19. In these patients, other factors, such as old age and comorbidities, may offset any protective effect of increased mucus or other biological mechanisms.

In summary, a number of factors may be acting in concert to drive a potential protective phenotype observed in SARS-CoV-2 infection in asthma suggested from the study by BEURNIER et al. [1], as summarised in figure 1. Large-scale longitudinal studies incorporating sampling, such as that being undertaken by the International Severe Acute Respiratory Infection Consortium (ISARIC), should shed light on how immune responses to SARS-CoV-2 differ in individuals with and without asthma. Trials of recombinant human ACE2 (NCT04335136) and ICS (NCT04416399, NCT04355637) are also ongoing, the results of which are eagerly awaited. Understanding the basis of differences in susceptibility to severe COVID-19 between asthmatic and non-asthmatic populations may ultimately offer important insights into therapeutically exploitable targets to reduce the overall burden of COVID-19.

Hugo Farne (1) and Aran Singanayagam

National Heart and Lung Institute, Imperial College, London, UK.

Correspondence: Aran Singanaygam, National Heart and Lung Institute, Norfolk Place, London W2 1PG, UK.

E-mail: a.singanayagam@imperial.ac.uk

Received: 6 Aug 2020 | Accepted after revision: 23 Oct 2020

Conflict of interest: H. Farne has nothing to disclose. A. Singanayagam has nothing to disclose.

\section{References}

1 Beurnier A, Jutant EM, Jevnikar M, et al. Characteristics and outcomes of asthmatic patients with COVID-19 pneumonia who require hospitalisation. Eur Respir J 2020; 56: 2001875.

2 Myles PR, Semple MG, Lim WS, et al. Predictors of clinical outcome in a national hospitalised cohort across both waves of the influenza A/H1N1 pandemic 2009-2010 in the UK. Thorax 2012; 67: 709-717. 
3 Kloepfer KM, Olenec JP, Lee WM, et al. Increased H1N1 infection rate in children with asthma. Am J Respir Crit Care Med 2012; 185: 1275-1279.

4 Dawood FS, Kamimoto L, D'Mello TA, et al. Children with asthma hospitalized with seasonal or pandemic influenza, 2003-2009. Pediatrics 2011; 128: e27-e32.

5 Booth CM, Matukas LM, Tomlinson GA, et al. Clinical features and short-term outcomes of 144 patients with SARS in the greater Toronto area. JAMA 2003; 289: 2801-2809.

6 Peters MC, Sajuthi S, Deford P, et al. COVID-19-related genes in sputum cells in asthma. Relationship to demographic features and corticosteroids. Am J Respir Crit Care Med 2020; 202: 83-90.

7 Finney LJ, Glanville N, Farne H, et al. Inhaled corticosteroids downregulate the SARS-CoV-2 receptor ACE2 in COPD through suppression of type I interferon. J Allergy Clin Immunol 2020; in press [https://doi.org/10.1016/j. jaci.2020.09.034].

8 Chauhan AJ, Inskip HM, Linaker $\mathrm{CH}$, et al. Personal exposure to nitrogen dioxide $\left(\mathrm{NO}_{2}\right)$ and the severity of virus-induced asthma in children. Lancet 2003; 361: 1939-1944.

9 Jha A, Dunning J, Tunstall T, et al. Patterns of systemic and local inflammation in patients with asthma hospitalised with influenza. Eur Respir J 2019; 54: 1900949.

10 Zein JG, Love TE, Erzurum SC. Asthma is associated with a lower risk of sepsis and sepsis-related mortality. Am J Respir Crit Care Med 2017; 196: 787-790.

11 Krishack PA, Wang K, Rzhetsky A, et al. Preexisting type 2 immune activation protects against the development of sepsis. Am J Respir Cell Mol Biol 2017; 57: 628-630.

12 Groneberg DA, Eynott PR, Lim S, et al. Expression of respiratory mucins in fatal status asthmaticus and mild asthma. Histopathology 2002; 40: 367-373.

13 Ehre C, Worthington EN, Liesman RM, et al. Overexpressing mouse model demonstrates the protective role of Muc5ac in the lungs. Proc Natl Acad Sci USA 2012; 109: 16528-16533. 